\title{
EKSTENSION FUNNEL DAN FUNNEL STAND UNTUK MEMPERMUDAH MEMASUKKAN CAIRAN ASPAL KE PICNOMETER 50 ML GUNA MENGUKUR MASSA JENIS ASPAL
}

\author{
Adi Wiyono \\ Jurusan Teknik Sipil Politeknik Negeri Malang, Indonesia \\ Adiwiyono@gmail.com \\ (Artikel diterima: Oktober 2019, direvisi: September 2019, diterima untuk terbit: Januari 2020)
}

\begin{abstract}
Picnometer is a tool made of glass that has a shape that resembles a perfume bottle. Picnometer is a tool used to measure density or fluid density. There are various sizes of picnometer, but what is often used in the laboratory is the size of $50 \mathrm{ml}$. Constraints that often occur when measuring density are measurements that cannot run optimally and result in specific gravity taking takes longer. The reason is when moving the asphalt liquid to an asphalt liquid picnometer about the neck of the picnometer, so that repetitive displacement is carried out. When measuring material density, the asphalt temperature ranges from $150^{\circ} \mathrm{C}-170^{\circ} \mathrm{C}$. Here a PLP (Education Laboratory Staff) of Malang State Polytechnic makes an improvement on the asphalt liquid density. Modifying asphalt density measuring aids, namely funnel extension (funnel) and funnel stand. With the modification, it is hoped that the density measuring instrument can function optimally and become an international standard laboratory..
\end{abstract}

Keywords: Picnometer, extension funnel, funnel stand

\section{Pendahuluan}

Picnometer dalam laboratorium Teknik Sipil di Politeknik Negeri Malang, yang sering digunakan untuk mengukur berat jenis zat cair terutama cairan aspal sering menggunakan picnometer dengan ukuran 50ml. Dalam melakukanpengukuran massa jenis zat cair aspal menggunakan alat picnometer $50 \mathrm{ml}$ dan funnel ( corong ) yang terbuat dari tembaga. Kendala yang sering terjadi pada saat pengukuran massa jenis adalah pengukuran tidak bisa berjalan dengan optimal dan mengakibatkan pengukuran berat jenis memakan waktu yang lebih lama. Penyebabnya pada saat memindahkan cairan aspal ke picnometer cairan aspal mengenai leher picnometer, sehingga dilakukan pemindahan berulang - ulang. Pada saat melakukan pengukuran massa jenis bahan, suhu aspal berkisar $150^{\circ} \mathrm{C}$ $170^{\circ} \mathrm{C}$.

Disini seorang PLP ( Pranata Laboratorium Pendidikan ) Politeknik Negeri Malang membuat sebuah improvement ( inovasi perbaikkan ) pada alat pengukur massa jenis cairan aspal. Memodifikasi alat bantu ukur massa jenis aspal yaitu ekstension funnel (corong) dan funnel stand. Dengan ada modifikasi berharap alat ukur massa jenis dapat berfungsi dengan optimal dan menjadi laboraturium yang berstandar internasional. Sehingga perlu dilakukan kajian penelitian tentang “ Ekstension Funnel Dan Funnel Stand Untuk Mempermudah Memasukkan Cairan Aspal Kepicnometer 50ml Guna Mengukur Massa Jenis Aspal”.

\section{Tinjauan Pustaka}

Aspal adalah suatu bahan bentuk padat atau setengah padat berwarna hitam sampai coklat gelap, bersifat perekat ( cementious ) yang akan melembek dan meleleh bila dipanasi. Aspal tersusun terutama dari sebagaian besar bitumen yang kesemuanya terdapat dalam bentuk padat atau setengah padat dari alam atau hasil pemurnian minyak bumi, atau merupakan campuran dari bahan bitumen dengan minyak bumi atau derivatnya ( ASTM, 1994 ). Bitumen ( The Asphalt Institute,
1993 ) adalah suatu campuran dari senyawa hidrokarbon yang berasal dari alam atau dari suatu proses pemanasan, atau berasal dari kedua proses tersebut, kadang - kadang disertai dengan derivatnya yang bersifat non logam, yang dapat berbentuk gas, cairan, setengah padat atau padat dan campuran tersebut dapat larut dalam karbondisulfida ( CS2 ). Aspal yang dipakai dalam kontruksi jalan mempunyai sifat fisis yang penting, antara lain : kepekatan ( consistency), ketahanan lama atau ketahanan terhadap pelapukan oleh karena cuaca, derajat pengerasan, dan ketahanan terhadap air.

Tabel 2.1 Standart Pengujian dan Persyaratan Aspal Pen. 60/70

\begin{tabular}{|c|l|c|c|c|c|}
\hline No & \multicolumn{1}{|c|}{ Sifat } & Metode & Satuan & \multicolumn{2}{|c|}{ Persyaratan } \\
\hline 1 & Penetrasi & SNI 06-2456-1991 & $0,1 \mathrm{~mm}$ & 60 & 79 \\
\hline & $(25 \mathrm{C}, 100$ gr, 5 detik ) & & & & \\
\hline 2 & Titik lembek & SNI 06-2434-1991 & ${ }^{\circ} \mathrm{C}$ & 48 & 58 \\
\hline & ( ring and ball test ) & & & & \\
\hline 3 & Titik nyala & SNI 06-2433-1991 & ${ }^{\circ} \mathrm{C}$ & 200 & \\
\hline & ( clevland open cup ) & & & & \\
\hline 4 & Dakilitas & SNI 06-2432-1991 & $\mathrm{cm}$ & 100 & \\
\hline & (25 C, 5 cm permenit ) & & & & \\
\hline 5 & Berat jenis ( 25 C ) & SNI 06-2488-1991 & $\mathrm{gr} / \mathrm{cm} 3$ & 1 & \\
\hline
\end{tabular}

\section{A. Picnometer}

Picnometer adalah alat yang berfungsi mengukur nilai suatu massa type atau densitas dari fluida. Picnometer terbuat dari bahan kaca dan berwujud mirip botol parfum. Praktikum yang diukur biasanya adalah massa type dari oli dan termasuk minyak goreng. Picnometer juga dipakai untuk pengukuran material berpori seperti batuan, sampel yang dapat diukur massa jenisnya perlu dihaluskan khususnya dahulu hingga berupa serbuk / serpihan. Dengan demikian pori - pori amat hilang dalam sampel yang berupa serbuk.

\section{B. Funnel}

Funnel ( corong ) alat laboratorium secara umum alat ini terbagi menjadi berbagai jenis yaitu funnel yang menggunakan karet atau plastik dan funnel yang menggunakan glass ( kaca). Bagian dari funnel terdiri dari mulut dan batang funnel. Funnel glass juga memiliki ukuran dari terkecil hingga terbesar panjangnya sesuai dengan 
diameter atas corong, ukuran diameter 50, 75, 100, 150, dan $200 \mathrm{~mm}$. Sehingga dalam prakteknya dapat dengan mudah memasukkan cairan kedalam wadah yang digunakan untuk praktek. Funnel stand ( penyanggah corong ) berfungsi sebagai tempat meletakkan corong.

\section{METODE PENELITIAN}

\section{A. Lokasi Penelitian}

Perancangan ekstension funnel dan funnel stand dilakukan di laboratorium bahan jalan raya Jurusan Teknik Sipil Politeknik Negeri Malang.

\section{B. Perancangan}

Berikut adalah desain perancangan ekstension funnel dan funnel stand.
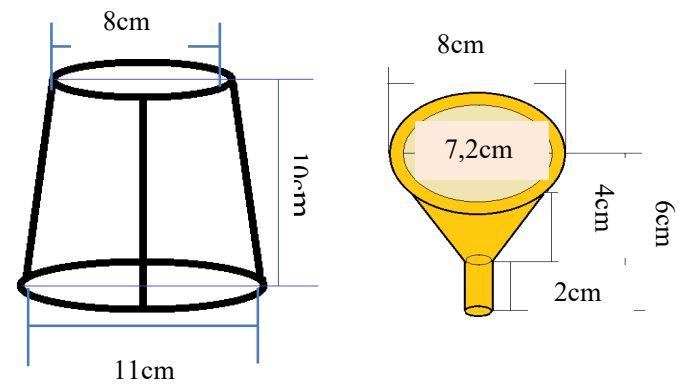

Gambar 1. Rancangan Funnel Stand dan Ekstension Funnel

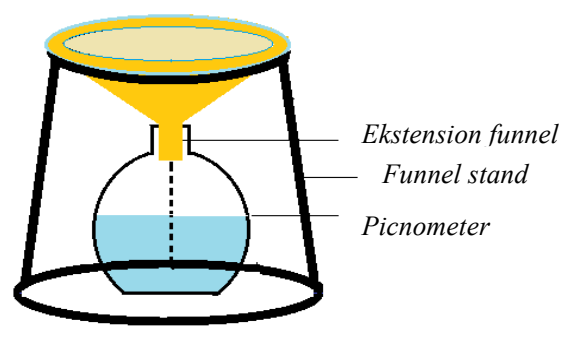

Gambar 2. Rancangan Keseluruhan

\section{Bahan Penelitian}

Bahan yang digunakan dalam penelitian antara lain :

- $\quad$ Funnel (corong) bahan tembaga.

- Pipa tembaga 1 lonjor dan ukuran diameter $6 \mathrm{~mm}$.

- Besi tulangan 1 lonjor dan ukuran diameter 6 mm.

\section{Peralatan Penelitian}

Peralatan-peralatan yang digunakan dalam penelitian ini antara lain :

- Las kuningan.

- $\quad$ Las listrik (elektroda).

- Gerenda potong besi.

- Jangka sorong

- Meteran

- Rool besi

\section{E. Prosedur Pembuatan Ekstension Funnel dan Funnel} Stand

Prosedur pembuatan ekstension funnel dan funnel stand sebagai berikut:

\section{Pembuatan ekstension funnel}

Pembuatan ekstension funnel (leher corong) menggunakan bahan funnel (corong) tembaga dan pipa tembaga ukuran lubang $6 \mathrm{~mm}$ dan panjang $25 \mathrm{~mm}$. Berikut cara perancangan ekstension funnel ( leher corong) :

- Membuat desain untuk pembuatan ekstension funnel (Leher corong).

- Mengukur lubang funnel (corong) tembaga dan panjang pipa tembaga sesuai kebutuhan dan fungsinya. Dengan menyesuaikan lubang dan leher picnometer.

- Memotong pipa tembaga dengan ukuran panjang $25 \mathrm{~mm}$.

- Selanjutnya dilakukan penyambungan funnel (corong) tembaga dan pipa tembaga dengan panjang $25 \mathrm{~mm}$ dengan cara pengelasan kuningan.

- Setelah dilakukan penyambungan dilalukukan pengujian ekstension funnel aplikasi ke picnometer dengan cara memindahkan atau menuangkan air ke ekstension funnel untuk menguji kebocoran. Bila tidak ada kebocoran berarti proses penyambungan berjalan dengan baik dan sesuai dengan fungsinya.

\section{Pembuatan Funnel Stand}

Pembuatan funnel stand (penyanggah corong) Menggunakan bahan dari besi tulang dengan ukuran ketebalan $6 \mathrm{~mm}$ dan panjang $30 \mathrm{~cm}$. Berikut cara perancangan funnel stand (penyanggah corong):

- Membuat desain untuk pembuatan funnel stand.

- Mempersiapkan bahan dari besi besi tulangan ketebalan $6 \mathrm{~mm}$ dan panjang $30 \mathrm{~cm}$.

- $\quad$ Membuat 2 lingkaran dengan ukuran diameter atas 7,5 $\mathrm{cm}$ dan diameter bawah $10,5 \mathrm{~cm}$. Setelah besi tulangan dirol menjadi lingkaran selanjutnya membuat tiga penyanggah untuk kedua lingkaran dengan ukuran panjang $9,5 \mathrm{~cm}$.

- $\quad$ Setelah bahan sudah dilakukan pengerollan dan batang penyanggah, selanjutnya dilakukan pengelasan menggunakan las listrik (elektroda).

- Setelah perancangan funnel stand (penyanggah corong) selesai, selanjutnya dilakukan pengujian alat dengan memasangkan funnel dan picnometer dengan hasil perancangan sesuai desain dan fungsinya.

\section{Prosedur Pengujian Ekstension Funnel Dan Funnel Stand}

Pengujian ini dilakukan untuk mengetahui hasil perancangan dan fungsi aplikasi ekstension funnel dan funnel stand (penyanggah corong). Adapun prosedur pengujian adalah sebagai berikut :

- Pengujian aplikasi ekstension funnel dan funnel stand (penyanggah corong) terhadap picnometer.

- Pengujian pengukuran massa jenis cair aspal dengan menggunakan ekstension funnel dan funnel stand ( penyanggah corong).

- Pengujian waktu dan akurasi pengukuran dengan alat yang terdahulu dan alat yang menggunakan ekstension funnel dan funnel stand (penyanggah corong).

\section{PERANCANGAN DAN HASIL PENGUJIAN}

Perancangan ekstension funnel dan funnel stand merupakan modifikasi dari alat yang sudah ada di 
laboraturium bahan jalan raya Jurusan Teknik Sipil Politeknik Negeri Malang. Dalam perancangan ekstension funnel dan funnel stand menggunakan tambahan modifikasi pada alat funnel ( corong) dan funnel stand ( penyanggah corong ).

Perancangan ini dapat mengetahui kebutuhan material dan guna pada alat pengukuran massa jenis aspal. Kebutuhan dan bahan untuk perancangan ekstension funnel, dengan menggunakan bahan - bahan yang dipilih untuk perancangan ekstension funnel dan funnel stand. Dalam perancangan ini membutuhkan material yang sesuai dengan alat pengukuran massa jenis aspal guna mendapakan hasil pengukuran yang optimal.

Table 1. Komponen Utama Ekstension Funnel dan Stand Funnel

\begin{tabular}{|c|l|c|}
\hline No & $\begin{array}{c}\text { Komponen dan Alat Ekstension Funnel dan } \\
\text { Stand Funnel }\end{array}$ & Jumlah \\
\hline 1 & Besi tulangan ukuran 6 mm & $\begin{array}{c}1 \\
\text { lonjor }\end{array}$ \\
\hline 2 & Pipa tembaga ukuran diameter 6 mm & $\begin{array}{c}1 \\
\text { lonjor }\end{array}$ \\
\hline 3 & Funnel (corong ) tembaga & 1 \\
\hline 4 & Mesin las listrik & 1 \\
\hline 5 & Mesin las tembaga ( las asetelin ) & 1 \\
\hline 6 & Gerenda tangan & 1 \\
\hline 7 & Jangka sorong & 1 \\
\hline 8 & Meteran & 1 \\
\hline 9 & Roll besi & 1 \\
\hline
\end{tabular}

\section{A. Perancangan Ekstension Funnel dan Funnel Stand}

Secara garis besar praktek pengukuran massa jenis aspal menggunakan alat picnometer $50 \mathrm{ml}$ dan mnggunakan funnel ( corong ) tembaga dengan alat bantu penjapit funnel ( corong ). Dalam proses praktek ini sering mengalami kendala dalam proses pengukuran massa jenis aspal, sehingga pengukuran kurang optimal dan dilakukan berulang - ulang.

Dari permasalahan proses perhitungan massa jenis aspal, maka dilakukan modifikasi alat. Modifikasi dengan perancangan ekstension funnel dan funnel stand, perancangan ini bertujuan dalam praktek pengukuran massa jenis aspal. Adanya modifikasi ini pengukuran dapat dilakukan dan hasil perhitungan optimal. Maka ada beberapa hal dalam perancangan ekstension funnel dan stand funnel adalah sebagai berikut :

\section{a. Perancangan Ekstension Funnel}

- Penentuan bahan atau material

1. Funnel ( corong ) tembaga.

2. Pipa tembaga dengan ukuran diameter $6 \mathrm{~mm}$.

3. Kawat tembaga.

4. Gerenda potong.

- Perancangan.

1. Pembuatan desain rancangan.

2. Pemotongan pipa tembaga dengan ukuran $2 \mathrm{~cm}$.

3. Melakukan penyambungan pipa tembaga dengan funnel ( corong ) tembaga dengan menggunakan las asetelin.

4. Setelah itu funnel ( corong ) dirapikan dan dilakukan ujicoba pada picnometer $50 \mathrm{ml}$ dan ujicoba kebocoran dengan air atau cairan.
5. Setelah pengujian dan hasilnya optimal, maka alat ekstension funnel dapat dipergunakan.

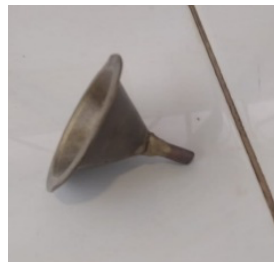

Gambar 3. Hasil modifikasi ekstension funnel

\section{b. Perancangan Funnel Stand}

- Penentuan bahan atau material

1. Besi tulangan dengan ukuran $6 \mathrm{~mm}$.

2. Kawat las listrik.

3. Gerenda potong.

- Perancangan

1. Membuat desain rancangan.

2. Pemotongan besi tulangan

3. Setelah itu dilakukan pengerolan dengan ukuran diameter $8 \mathrm{~cm}$ dan $11 \mathrm{~cm}$.

4. Setelah itu melakukan penyambungan dengan cara pengelasan menggunakan mesin las.

5. Setelah dilakukan pengelasan funnel stand dirapikan. Setelah itu funnel stand dilakukan pengujian pada ekstension funnel dan picnometer.

6. Setelah melakukan pengujian alat dan hasilnya optimal, funnel stand dapat dipakai untuk pengukuran massa jenis aspal.

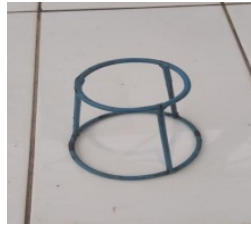

Gambar 4. Hasil funnel stand

\section{Hasil Pengujian}

\section{A. Metode Lama}

Dari pelaksanaan pengujian alat pengukuran massa jenis aspal menggunakan alat yang lama pada pengukuran mengalami kendala. Metode lama pengukuran pada saat menuangkan cairan aspal ke funnel ( corong ) masih menggunakan penjapit funnel ( corong ), sehingga pada saat penuangan cairan aspal dilakukan oleh 2 orang. Orang pertama menjapit funnel ( corong ) memposisikan ke picnometer dengan tepat dan orang kedua menuangkan cairan aspal. Belum lagi kendala pada saat penuangan cairan aspal mengenai bibir lubang picnometer, pada saat pengukuran cairan aspal tidak boleh menetes ke dinding leher lubang pinometer. Sehingga pengukuran harus diulangi lagi dan picnometer dibersihkan. Kendala seperti ini kurang efektif dan efisien 


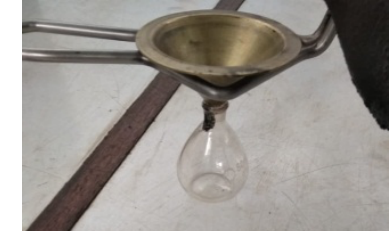

Gambar 5. Metode lama

\section{B. Metode Baru}

Dari pelaksanaan pengujian alat pengukuran massa jenis aspal menggunakan ekstension funnel dan funnel stand. Pengukuran dengan metode baru cukup dilakukan dengan 1 orang. Ekstension funnel dan funnel stand tanpa menguatirkan cairan aspal mengenai dinding leher lubang picnometer pada saat penuangan cairan aspal. Metode baru ini lebih efektif dan efisien.

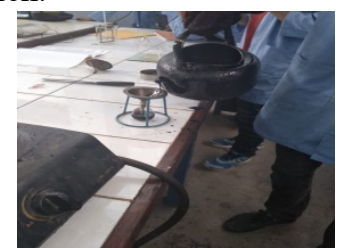

Gambar 6. Metode baru

\section{Pembahasan}

Dari hasil pengujian pengukuran menggunakan metode lama dan metode baru. Perbandingan pengukuran menunjukkan metode baru lebih efektif dan efisien daripada menggunakan metode lama. Alat ekstension funnel dan funnel stand menunjukkan perancangan modifikasi alat mendapatkan hasil yang optimal pada saat praktek pengukuran massa jenis aspal.

\section{Luaran Yang Dicapai}

- Luaran yang dari penelitian ini adalah buku laporan.

- $\quad$ Artikel / jurnal lokal Politeknik Negeri Malang.

\section{KESIMPULAN DAN SARAN}

\section{A. Kesimpulan}

Hasil perancangan ekstension funnel dan funnel stand yang telah dibuat. Alat tersebut sangat membantu dalam proses praktek pengukuran massa jenis aspal dibandingkan metode pengukuran massa jenis aspal yang sebelumnya. Setelah ada modifikasi atau improvement pada alat ukur massa jenis aspal pengukuran menunjukkan hasil yang optimal. Pelaksanaan praktek pengukuran massa jenis aspal lebih cepat, efektif dan efisien.

\section{B. Saran}

Alat ekstension funnel dan stand funnel untuk praktek pengukuran massa jenis aspal harus dilakukan perawatan agar alat bersih dan terjaga. Sehingga alat dapat dipakai untuk mahasiswa dan mahasiswi jurusan Teknik Sipil Politeknik Negeri Malang berikutnya.

\section{DAFTAR PUSTAKA}

[1] Bredthaue, wilhem et all. 1993. Impulse Physics Jilid 1. Stuttgard: Ernstklett Schubuchvelag.

[2] Claudia Agustin, 2013. Berat Jenis Dan Massa Jenis Cair Dan Zat Padat. Jember:Universitas Jember.

[3] Halliday dan Resnick, 1991. Fisika Jilid 1. Jakarta : Erlangga.

[4] Kanginan, M.20020Fisika.Jakarta: Gramedia.

[5] Searss,FW dan M. W. Zeamansky. 1981. Fisika Untuk Universitas Jilid 1. Bandung: Bina Cipta.

[6] SNI 06-2488-1991, Metode Pengujian Berat Jenis Aspal

[7] RSNI S-01-2003, Spesifikasi Aspal Berdasarkan Penetrasi

[8] www.glasswareindonesia.com 2017. Picnometer

[9] www.katanyes.com 2017. 10 Alat - alat Sederhana di Laboraturium Kimia Berserta Fungsinya 